\title{
USING DESIGN COMPETITIONS TO TEACH DESIGN
}

\author{
Petkau, D.S \\ Department of Biosystems Engineering, University of Manitoba, Winnipeg Canada
}

petkau@cc.umanitoba.ca

\section{INTRODUCTION}

Design education has become an important part of the curriculum in engineering schools. Design courses are set up to allow students to learn techniques and then to implement the techniques for better understanding. Schools currently are challenged to overcome the limitations of time, resources, and on how to fit this into the current curriculum. An alternative and unofficial method of teaching design is in the many student design competitions that are available. In most cases these are student run with very little input by the educational institute. Yet our understanding is that many large employers of engineering students would prefer to hire graduates with experience on these design teams. I would like to discuss the challenges of implementing and maintaining a student design team. I would also like to discuss the principle of using these design teams as a more formal method of teaching design to engineering students.

\section{BACKGROUND}

I would like to start by summarizing the rules and regulations of a particular design competition. I will use the American Society of Agricultural and Biological Engineers (ASABE) International Quarter Scale Tractor Competition (IQS). There are many of these student design competitions each with their own set of rules and regulations. While there are differences in each of the particular competitions, the general learning outcome of each competition is to teach students the many aspects of the design process.

The importance of these parameters is not just on the learning outcomes for the students but also in the challenges of maintaining student membership. The rules place restrictions on who can be involved and how they must conduct themselves. This teaches the students some of the responsibilities of professional membership but also makes it more restrictive to ongoing membership.

The objective of this competition is that the students are expected to act as engineers of a leading agricultural machinery company. The goal of the team is to develop a machine, which is compact in size, inexpensive, and can harness the specific engine power to achieve maximum pulling power for short periods of time. The tractor will be introduced to the general market assuming a set selling price and sold units per year. It is up to each team to identify a target market and develop a tractor for this market. They must control the production costs to show profitability. Students are expected to build a business case to make the most money by taking a certain market share or by matching market demand with reducing the production cost.

The deliverables for the competition are as follows:[1]

1. Design Report (description of design) Includes; conceptual stage, fabrication, testing, development

2. Design Log (notes, meetings, calculations)

3. Cost Estimate Report Includes; overview (profit margin, cost to produce, etc.), cost, strategy, cost analysis, cost estimate component breakdown

4. Team Presentation Includes; design concept/ customer focus, readiness for market, user safety, product cost, team organization/ planning

5. Design Judging

Includes; manufacturability, serviceability, ergonomics, safety, testing and development

6. Sound Judging

7. Technical Inspection

8. Maneuverability

9. Tractor Pull

As can be seen from the extensive deliverables, this competition is designed to simulate a real life manufacturing design challenge.

There are also a complete set of rules and regulations [1] for the competition of which I am only going to focus on the eligibility of the team members. The rules state that all team members must be enrolled for at least one semester as a student and be a student member of ASABE. The tractor must be designed entirely by the student team members without involvement from outside professionals or faculty. It is encouraged that the majority of the fabrication be performed by the students.

\section{DISCUSSION}

The question now is how we can use these design competitions to teach design. Currently students are learning many engineering design attributes on their own through hands on experience. Since the competition rules state that the students should work on their own they generally want to be self regulated. My experience is that the students learn more quickly than in a classroom setting. They are more reliant on each other and are required to get things right the first time as rework costs money which is a constraint. The question is how this knowledge aligns with the engineering knowledge taught based on CEAB requirements. I will now evaluate this based on the 12 graduate attributes.

A knowledge base for engineering - Students in the IQS competition are required to design and build their own tractor each year. This requires knowledge of base level mathematics, natural sciences, and engineering fundamentals for the basic initial design.

Problem analysis - Once the base design is complete students need to analyze and solve more complex problems to develop their design to meet both marketing and performance goals in a unique method.

Investigation - Students are required to conduct investigations to solve complex problems through analysis, physical testing, and computer simulation.

Design - Students are required to produce solutions to their design systems that meet specified needs with appropriate attention to health and safety risks, applicable standards, and economic, environmental, cultural and societal considerations

Use of engineering tools - The construction of the design is completely carried out by team members using a variety of tools from computer based to machine based.

Individual and team work - The design is a combination of individual tasks that must be coordinated to complete the whole. Students on the teams come from different years in the program and from different programs. The work is carried out on their own time and so team work and coordination is vital to having a product in the given time constraint. Communication skills - There is a requirement to produce a design report, and presentation.

Professionalism - Students are expected to act as engineering professionals.

Impact of engineering on society/ environment - Teams must evaluate the current marketplace, including social and environmental impacts in order to target their market.

Ethics and equity - Students are expected to apply professional ethics, accountability, and equity.

Economics and project management - The teams must submit an extensive cost report.

Life-long learning - Students generally contribute to the design team for more than a single year. Returning students are excellent at mentoring and directing new members in the which contributes to both parties advancement of knowledge

The student design competitions require the students to gain leaning in all 12 of the graduate attributes. There are a number of challenges to this method of student learning including: academia has no method of evaluating individual student learning, academia has no method of directing the learning outcomes, students are restricted by time constraints, students receive very little recognition for the learning. Even with these challenges we see students returning each year to contribute and learn from these design competitions. An obvious solution to some of the challenges is to develop this work into courses for credit. But that brings with it a whole new set of constraints and challenges.

\section{REFERENCES}

1. American Society of Agricultural and Biological Engineers. 1/4 Scale Tractor International Student Design Competition Page. http://www.asabe.org/students/tractor/asaecomp.html. Accessed May 4, 2011. 